\title{
Discursos organizacionais: as relações de consumo no ambiente das redes sociais digitais
}

Organizational discourses: consumer relations in the environment of the digital social networks

Discursos organizacionales: las relaciones del consumo en el ambiente de las redes sociales digitales

\section{Elizabeth Moraes Gonçalves}

- Doutora em Comunicação Social pela Universidade Metodista de São Paulo (Umesp)

- Mestre em Língua Portuguesa pela Pontifícia Universidade Católica de São Paulo (PUC-SP)

- Graduada em Letras pela Umesp

- Desde 1999, docente do programa de Pós-Graduação em Comunicação Social da Umesp

- Coordenadora do grupo de pesquisa "Estudos de comunicação e linguagem - Coling", da Umesp

- Autora do livro Propaganda \& Linguagem: análise e evolução

- Organizadora e co-organizadora de uma série de coletâneas, entre as quais: Práticas comunicacionais: sujeitos em (re)ação e Comunicação organizacional: externa, responsável, multidisciplinar.

- E-mail: bethmgoncalves@terra.com.br

Vanda de Souza Machado

- Mestranda no Programa de pós-graduação em Comunicação Social da Universidade Metodista de São Paulo (Umesp)

- Graduada em Comunicação Social - Publicidade e Propaganda pela Universidade Cruzeiro do Sul (Unicsul)

- Fez extensão universitária em Gerência de Produtos pela Fundação Getúlio Vargas (FGV)

- E-mail:vandadesouza@uol.com.br 


\section{Resumo}

As organizações, na contemporaneidade, tendem a buscar novos modos de relacionamentos com seus públicos; o desafio é inseri-los num clima colaborativo, na construção de produtos e na propagação das marcas pelas redes sociais digitais. 0 texto apresenta elementos teóricos que propiciam uma discussão sobre esse fenômeno das relações de mercado, de consumo e de linguagem, além de ilustrar a discussão com casos de propaganda participativa. A interação de fato acontece quando, por meio da linguagem, se estabelecem contratos (ainda que informais) de parceria na criação e produção de mensagens. Quando inserido na construção de novos produtos ou serviços, o consumidor élevado a engajar-se na propagação do conteúdo pelas mídias sociais.

\section{PALAVRAS-CHAVE: COMUNICAÇÃO • LINGUAGEM・DISCURSO • CONSUMO • COCRIAÇÃO • MÍDIAS SOCIAIS DIGITAIS.}

\section{Abstract}

Nowadays organizations tend to seek new forms of relationship with their stakeholders; the challenge is to insert them in a collaborative atmosphere, for construction of products and in the divulgement of brands through the digital social networks. The text presents theoretical elements that provide a discussion of this phenomenon of market relations, of consumption and of language, in addition to illustrating the discussion with cases of collaborative advertising. The interaction actually takes place when, by means of the language, the persons establish contracts (even if informal) of partnership in the creation and production of messages. When inserted in the development of new products or services, the consumer is led to engage in spreading the content through the social media.

KEYWORDS: COMMUNICATION • LANGUAGE •SPEECH・CONSUMPTION •CO-CREATION・DIGITAL SOCIAL MEDIA.

\section{Resumen}

Las organizaciones, en la actualidad, tienden a buscar nuevas formas de relaciones con sus grupos de interés; el reto es insertarlos en un clima colaborativo, en la construcción de productos y en la propagación de marcas por las redes sociales digitales. El artículo presenta elementos teóricos que proporcionan una discusión de este fenómeno de las relaciones de mercado, de consumo y de lenguaje, además de ilustrar la discusión con casos de propaganda participativa. La interacción de hecho sucede cuando, por medio del lenguaje, se establecen contratos (aunque sean informales) de colaboración en la creación y la producción de mensajes. Cuando se lo inserta en la construcción de nuevos productos o servicios, el consumidor es conducido a comprometerse en la difusión del contenido por los medios sociales. 
$\mathrm{P}$

ensar em fidelização de clientes numa sociedade em que a comunicação está cada vez mais desmassificada tem sido um grande desafio para as organizações que até há pouco tempo tinham em suas mãos o domínio da comunicação de seus produtos, através de veículos consagrados como o rádio, a televisão, o jornal e as revistas. As mensagens seguiam uma padronização com o intuito de influenciar o consumidor a adquirir seus produtos. Já na década de 1980, Alvin Toffler (2014, p. 172), observou que estavam ocorrendo grandes mudanças nos meios de comunicação:

A desmassificação da civilização, que reflete e intensifica os meios de comunicação, traz com ela um enorme salto na quantidade de informação que todos trocaremos uns com os outros. E é este aumento que explica por que estamos nos tornando uma "sociedade de informação".

0 autor estava certo em suas previsões, as interfaces tecnológicas chegaram e mudaram definitivamente as formas de relacionamento das pessoas e isso repercutiu principalmente no mercado consumidor em que 0 indivíduo foi beneficiado por uma multiplicidade de aparatos tecnológicos que trouxeram o poder de se relacionar com um mundo de pessoas, de qualquer lugar, a qualquer hora. Além da troca de informações em tempo real, o indivíduo passou também a interagir e interferir nas estratégias organizacionais. As organizações por sua vez, imersas nessa sociedade de informação, perderam o controle da comunicação que circula a cada segundo nas redes sociais on-line e se depararam com um grande desafio de atrair os consumidores para suas marcas e engajá-los no compartilhamento entre suas redes de amigos.

Após 0 advento das redes sociais on-line, o indivíduo também passou a interagir com o outro numa nova ambiência que the conferiu uma oportunidade jamais experimentada na história, em que qualquer pessoa pode produzir seus próprios conteúdos, criar vídeos e publicar para uma multidão de pessoas. Surgiu também, a oportunidade de participar ativamente nos processos de criação de produtos e serviços em parceria com as organizações. Toffler $(2014$, p. 275) também já alertava sobre o nascimento desse consumidor pós-moderno, que além de consumir, também faria parte do processo de produção, ao que ele denominou de prossumidor.

E se a isto agora acrescentarmos a possibilidade de que muitas pessoas, dentro em breve, estarão trabalhando em casa ou nas cabanas eletrônicas de amanhã, começaremos a imaginar uma mudança significativa nas "ferramentas" acessíveis ao consumidor. Muitos dos mesmos dispositivos eletrônicos que usaremos em casa para fazermos trabalho remunerado também tornarão possível produzir mercadorias ou serviços para o nosso próprio uso. Neste sistema o prossumidor, que dominou as sociedades da Primeira Onda, será trazido de volta ao centro da ação econômica - mas numa Terceira Onda, em base de tecnologia.

\section{O NOVO CONSUMIDOR: PRODUZIR E CONSUMIR}

Nessa abordagem histórica, identificamos que, quase trinta anos antes do advento da internet, ao discutir os efeitos da automação elétrica nos processos de informação, Marshall McLuhan, teórico da comunicação, já vislumbrava o nascimento do prosumer. A obra original do autor é da década de 1960; neste trabalho buscamos a oitava edição em língua portuguesa, de uma tradução feita por Décio Pignatari:

A automação não afeta somente a produção, mas também o consumo e o mercado; pois, no circuito da automação, o consumidor se transforma em produtor -assim como o leitor da imprensa telegráfica em mosaico produz as suas próprias notícias ou simplesmente é suas próprias notícias (...) energia e produção tendem agora a fundir-se com a informação e o aprendizado. 0 mercado e 0 consumo tendem a formar um corpo único com o aprendizado, o esclarecimento e a absorção da informação (Mcluhan, 1996, p. 392).

Para Don Tapscott (2010, p.252), o fenômeno dos prosumers é "a manifestação de comunidades baseadas em interesses comuns que trabalham juntas para resolver um problema ou aprimorar um produto ou serviço". Com as tecnologias, tornou- 
se comum as pessoas se juntarem em comunidades em busca de soluções para os fins. As tecnologias estão cada vez mais proporcionando a qualquer pessoa produzir conteúdos relevantes, criar designers e produtores de bens e serviços.

Se o consumidor individual ganhou notoriedade e visibilidade, nessa nova configuração de mercado não há mais espaço para a comunicação unidirecional em que se pautavam as organizações. Aqui é preciso dialogar com o consumidor, inserindo-o num clima de cocriação, convidando-o a participar voluntariamente na construção de novos produtos, novos designs, novos sabores e também na produção de conteúdos favoráveis à marca.

Em meio a tantas mudanças ocorridas no campo da comunicação, a cocriação é uma que merece a nossa atenção. Por isso, este estudo visa oferecer elementos para a reflexão sobre como se estabelecem as relações de coparticipação entre organizações e consumidores, tendo como finalidade o engajamento dos participantes na construção de conteúdos e na propagação de informação para os seus pares.

\section{DAS MÍDIAS DE MASSA PARA AS INDIVIDUAIS}

Embora o conceito de marketing colaborativo aparentemente seja novo e fruto das mudanças ocorridas nos processos comunicacionais por meio das tecnologias de relacionamento, o modo interacional sempre fez parte da vida do ser humano. 0 que acontecia na configuração anterior, portanto, era que as relações ficavam restritas ao ambiente de poucos e, com a revolução digital, o indivíduo ganhou forças, pois a sua opinião passou a ser exposta a um volume ilimitado de pessoas, a qualquer hora, em qualquer lugar. 0 tempo e o espaço foram eliminados dessa nova forma de se comunicar. Nesse espaço público, "o eu on-line não se apoia em nenhum tipo de tempo, espaço ou corpo, é, sem dúvida, um presente" (Kerckhove, 2009, p. 221).

Nesse contexto, entende-se interatividade como uma atuação na criação, conforme conceito proposto por Lorenzo Vilches (2003, p. 234), como "a passagem da mediação para a criação. Os usuários deixam de ser objetos de manipulação para converter-se em sujeitos que manipulam". 0 manipular, que constantemente tem agregado um sentido pejorativo, assume aqui um sentido de transformar, de agir sobre a realidade em que se atua.

A relação entre os interlocutores, embora tenha ênfase no contexto da contemporaneidade, caracterizado pela evolução tecnológica, não é algo novo ou fruto da tecnologia, de tal forma que já se encontra no pensamento defendido por Michel Pêcheux (1990), de que o funcionamento da linguagem não se explica como simples informação, mas sim pela produção de sentidos pelos sujeitos e pelo jogo de efeitos de sentidos, carregados de ideologias.

Estamos imersos em uma cultura de convergência e nessa nova estrutura comunicacional a cultura participativa ea inteligência coletiva são os pilares que sustentam a sociedade em rede, Henry Jenkins (2008, p. 27), descreve a convergência como

um fluxo de conteúdos através de múltiplos suportes midiáticos, à cooperação entre múltiplos mercados midiáticos e ao comportamento migratório dos públicos dos meios de comunicação, que vão a quase qualquer parte em busca das experiências de entretenimento que desejam. Convergência é uma palavra que consegue definir transformações tecnológicas, mercadológicas, culturais e sociais, dependendo de quem está falando e do que imaginam estar falando.

Sem dúvida, essa nova maneira de atuação das mídias forçou um reposicionamento cultural por parte das organizações que desejam manter-se competitivas no mercado consumidor. Optar por uma comunicação dialógica e participativa é a escolha 


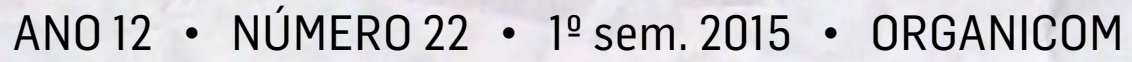 \\ DISCURSOS ORGANIZACIONAIS: AS RELAÇÕES DE CONSUMO NO AMBIENTE DAS REDES SOCIAIS DIGITAIS}

assertiva para quem está inserido na nova configuração da sociedade em rede, porque os consumidores têm demonstrado uma declinante aceitação das mídias tradicionais. Assim, "a convergência representa uma transformação cultural, à medida que consumidores são incentivados a procurar novas informações e fazer conexões em meio a conteúdos midiáticos dispersos" (Jenkins, 2008, p.28). É preciso conhecer as regras que compõem essa teia de relacionamentos e como se constituem as relações para alcançar êxito frente aos públicos de interesse. Como sugere Manuel Castells (2006), não se trata de estar na rede, e sim de como fazer o melhor uso das tecnologias proporcionadas por ela. Estamos vivendo uma revolução comunicativa que está ocasionando importantes transformações no relacionamento e convívio humano. Os processos comunicativos dos meios analógicos ocorriam numa vertente unidirecional da grande mídia para a grande massa e essa somente recebia as mensagens, refletia sobre elas ou não, mas não podia interagir com o produtor do conteúdo diretamente, diferentemente do que vivenciamos hoje, um processo no qual o conteúdo pode partir de qualquer indivíduo para a grande rede.

0 processo unidirecional que configurava a mídia de massa já não contempla os anseios de grande parte da sociedade contemporânea, que coloca o indivíduo como um ator social numa estrutura interativa, dialógica e multidirecional e que tem plenos poderes para emitir mensagens, construir conteúdos, interagir com outros indivíduos e, principalmente, interferir na sociedade. Para Lucia Santaella (2004, p. 163),

o emissor não emite mais mensagens, mas constrói um sistema com rotas de navegação e conexões. A mensagem passa a ser um programa interativo que se define pela maneira como é consultado, de modo que a mensagem se modifica na medida em que atende às solicitações daquele que manipula o programa. Essas manipulações se processam por meio de uma tela interativa ou interface que são lugar e meio para o diálogo.

Essa transformação midiática alcançou o seu ápice quando o indivíduo percebeu que ao invés de ficar exposto a mensagens emitidas de um único aparelho receptivo como a televisão, em que ele só recebia as mensagens, ele poderia ter acesso a diversas tecnologias portáteis como os celulares e computadores móveis, que não só lhe permitem receber mensagens como também produzir conteúdos e compartilhar com sua rede de amigos. Esse é um novo modelo comunicativo que tira 0 controle da informação das mãos da grande mídia e o submete ao indivíduo.

A empresa de mídia impressa e a rede de televisão são organizações hierárquicas que refletem os valores de seus proprietários. As novas mídias, por outro lado, dão o controle a todos os usuários. A distinção entre estrutura organizacional descendente e ascendente é uma questão fundamental para a nova geração. Pela primeira vez, os jovens assumiram o controle de elementos essenciais para uma revolução nas comunicações (Tapscott, 2010, p.33).

Embora a internet seja o meio preferido da nova geração, ainda há uma grande parcela da população que assiste à tevê. A pesquisa divulgada pela Secretaria de Comunicação Social (Secom) em 2014 aponta que 97\% dos entrevistados assistem à tevê, $61 \%$ ouvem rádio e $47 \%$ têm o hábito de acessar a internet. 0 que se percebe na pesquisa é que há uma projeção de queda para os meios de comunicação mais tradicionais entre o público mais jovem na faixa de 16 a 25 anos, onde a preferência pela tevê cai $70 \%$ e a citação à internet sobe $25 \%$, ficando o rádio com $4 \%$ e os demais com menções próximas de 0\%. A leitura dessa pesquisa nos leva a perceber que ainda há um vasto campo a ser conquistado pela tecnologia em nosso país, pois pouco mais que a metade da população, 53\%, nunca teve acesso à internet, mas os 47\% que têm acesso gastam em média 3:39 horas do seu dia on-line e a maioria, 63,6\%, passam seu tempo no Facebook, a principal página de relacionamento no momento.

O pensamento que determina a comunicação digital como um campo estratégico "que oferece a oportunidade de construir uma ruptura epistemológica encontra um argumento importante nas transformações da percepção, do significado e, 


\section{ANO 12 • NÚMERO $22 \cdot 1^{10}$ sem. 2015 - ORGANICOM \\ DISCURSOS ORGANIZACIONAIS: AS RELAÇÕES DE CONSUMO NO AMBIENTE DAS REDES SOCIAIS DIGITAIS}

consequentemente, na forma de interpretar o território e o espaço" (Di Felice, 2008, p. 42). Essa ideia também é referenciada por Castells (2006, p. 20), quando diz que "o que a sociedade em rede é atualmente não pode ser decidido fora da observação empírica da organização social e das práticas que dão corpo à lógica da rede".

A nossa sociedade vai deixando para trás, então, um modelo comunicativo de organização e difusão de conteúdos que se constituía por um conjunto de representantes ou pela minoria que ocupava posições de liderança no poder e começa a existir pela interação espontânea dos seus membros, que através de interações colaborativas redefinem e moldam continuamente 0 sistema. A sociedade de rede só subsiste através da colaboração e para manter-se vivo nessa sociedade é preciso interagir com seus públicos, criar estratégias comunicativas não mais voltadas para a grande massa, mas pensando no consumidor individual, que ao sentir-se inserido como parte do processo poderá responder como um agente de comunicação e difusão de conteúdos pela sua rede de amigos, em favor da marca. Claro que ainda há uma grande parcela da população que não utiliza as mídias digitais, mas grande parte, $47 \%$, já faz uso desse meio e tem gerado uma revolução no processo comunicativo das organizações que buscam adaptar-se às mudanças testando novas formas de relacionamento e interação com seus públicos de interesse.

\section{A CULTURA COLABORATIVA: UMA QUESTÃO DE LINGUAGEM}

A busca de diferentes formas de interação, de participação, é cada vez mais facilitada pelas tecnologias de comunicação, sobretudo em tempos de expansão em grande escala da internet e das redes sociais digitais. Porém, algo que parece tão moderno já faz parte da concepção bakhtiniana de linguagem, quando se tem o dialogismo como seu princípio constitutivo. Portanto, o autor nunca está sozinho. "O fato de ser ouvido, por si só, estabelece uma relação dialógica. A palavra quer ser ouvida, compreendida, respondida e quer, por sua vez, responder à resposta, e assim ad infinitum" (Bakhtin, 1997, p. 357). No caso da propaganda participativa esse efeito dialógico torna-se muito evidente, à medida que as empresas ou organizações em geral buscam, por meio da linguagem e na linguagem, estabelecer um contato permanente e atuante com seus públicos. Ao selecionar as formas de atuação pelas redes sociais digitais escolhem-se elementos linguísticos compatíveis com o repertório do público ou dos públicos que se pretende atingir. Não se trata simplesmente de recursos apelativos publicitários, mas de seleção de componentes responsáveis por determinar uma participação criativa suficiente para satisfazer tanto às empresas que propõem a participação quanto ao público, potencial criador e consumidor, de se sentir satisfeito e envaidecido a ponto de divulgar na rede a sua criação, tornando-se um parceiro.

Assim, o efeito dialógico da linguagem (seja entre textos, seja entre sujeitos) está na base do processo comunicacional, ainda que a troca efetiva entre sujeitos não se concretize, ou seja, o ato de tomar a palavra implica uma responsabilidade com o outro e determina o que dizer e a forma de dizer; o enunciado é elaborado considerando as condições de produção e tendo em vista uma possível condição da recepção, o conhecimento do que o outro espera daquele contexto de comunicação. Estamos envolvidos em um contexto comunicacional marcado pela interação, de fato, ou seja, de participação na criação de produtos e de mensagens. As organizações apostam no sucesso desse tipo de contribuição, pois, a mensagem publicitária não emerge de uma equipe profissionalmente contratada para esse fim, mas representa uma forma de atuação pela linguagem própria do grupo, portanto, com muitas possibilidades de credibilidade e de sucesso.

Temos, dessa forma, na propaganda participativa pelas redes sociais digitais, os sujeitos envolvidos nos jogos de linguagem, interlocutores do processo comunicacional, se relacionando a partir de determinadas condições estabelecidas e papéis a serem desempenhados, construindo um fenômeno particularmente dialógico. 0 discurso, portanto, é construído a 


\section{ANO $12 \cdot$ NÚMERO $22 \cdot 1^{\circ}$ sem. $2015 \cdot$ ORGANICOM \\ DISCURSOS ORGANIZACIONAIS: AS RELAÇÕES DE CONSUMO NO AMBIENTE DAS REDES SOCIAIS DIGITAIS}

partir de uma ação conjunta e não de uma linearidade, pois cada sujeito imprime à relação comunicativa aspectos que permitem o seu reconhecimento e exigem que as ideias sejam tratadas de uma forma e não de outra.

As transformações ocorridas no campo comunicativo têm levado as organizações, seja no campo privado, seja no público, a mudar seus conceitos em relação ao fluxo de informações. A linguagem unidirecional não combina mais com a sociedade contemporânea em que qualquer indivíduo dispõe de uma mídia móvel capaz de colocá-lo em contato com uma sociedade em rede e, dessa forma, participar e interferir nos processos das organizações. Sabemos que muitas organizações resistiram a esse novo modelo comunicativo devido à perda de controle que a sociedade em rede lhes confere, mas esse é um caminho sem volta. Os consumidores não ficam mais estáticos absorvendo apenas o conteúdo televisivo. Eles agora são móveis e estão buscando na rede informações, a todo tempo, com outras pessoas que são como ele, que não estão atrás de interesse comercial, mas simplesmente da troca de informações.

Outros termos vão surgindo para definir esse fenômeno da comunicação pós-Web 2.0 como o groundswell, apontado por Charlene Li e Josh Bernoff (2012, p. 10), que retratam o fator como "uma tendência social na qual as pessoas usam a tecnologia para obter o que desejam umas das outras, e não com instituições tradicionais como as corporações". E reforçam que esse "não é um movimento passageiro; ele representa uma forma importante, irreversível e completamente diferente de as pessoas se relacionarem com as empresas e com as outras pessoas". Ou seja, não há para onde fugir, as organizações devem estar atentas às mudanças, como alerta Wilson Bueno (2011, p. 94): "As organizações e seus representantes não ignoram que atravessamos uma nova era e que a administração do século XX, respaldada na centralização do poder, nas estruturas hierárquicas rígidas e no autoritarismo... não têm mais vez".

Estamos vivendo a cultura de convergência, "onde as velhas e as novas mídias colidem, onde mídia corporativa e mídia alternativa se cruzam, onde o poder do produtor de mídia e o poder do consumidor interagem de maneiras imprevisíveis" (Jenkins, 2008, p. 27). Nessa cultura, os consumidores apresentam características opostas ao que a antiga configuração de massa thes conferia:

Se os antigos consumidores eram tidos como passivos, os novos consumidores são ativos. Se os antigos consumidores eram previsíveis e ficavam onde mandavam que ficassem, os novos consumidores são migratórios, demonstrando uma declinante lealdade a redes ou a meios de comunicação. Se os antigos consumidores eram indivíduos isolados, os novos consumidores são mais conectados socialmente. Se o trabalho de consumidores de mídia já foi silencioso e invisível, os novos consumidores são agora barulhentos e públicos (Jenkins, 2008, p.46).

Tapscott (2010, p. 51) define essa geração guiada pela tecnologia como a Geração Internet, a geração que está transformando os mercados por meio da cultura colaborativa, que propõe a interação entre os usuários e as organizações, numa parceria para a construção de novos produtos e serviços:

Os integrantes da Geração Internet estão transformando os mercados e o marketing, não apenas porque têm poder de compra e influência enormes. Eles também valorizam características diferentes de produtos e serviços e querem que as empresas criem experiências grandiosas. As maneiras [como] influenciam a si mesmos e a outras gerações são novas, e a mídia tradicional é ineficaz para atingi-los. (...) Em vez de consumidores, eles querem ser prosumers - coinovando produtos e serviços com os fabricantes (Tapscott, 2010, p. 51).

Algumas organizações ainda estão temerosas em relação ao futuro da sociedade em rede, outras já estão atuando nas redes e buscando novas formas de se relacionar com o novo consumidor. Embora o controle do consumidor não esteja mais nas mãos das organizações, é possível, sim, criar estratégias de comunicação que possam influenciá-lo a trabalhar 


\section{ANO $12 \cdot$ NÚMERO $22 \cdot 1^{0}$ sem. $2015 \cdot$ ORGANICOM \\ DISCURSOS ORGANIZACIONAIS: AS RELAÇÕES DE CONSUMO NO AMBIENTE DAS REDES SOCIAIS DIGITAIS}

em favor da marca. Há pouco tempo, as organizações para falar com seus públicos investiam milhões em divulgação na grande mídia. Com a chegada da internet, "isto não é mais verdade. A internet mudou as regras. Hoje, as organizações se comunicam diretamente com os consumidores" (Scott, 2008, p. 9). Essa possibilidade trouxe também poder para as organizações que conseguem monitorar, em tempo real, o que o mercado consumidor está falando sobre seus produtos, a tempo de mudar suas estratégias antes que o lucro de seus negócios seja prejudicado.

O que percebemos nas redes sociais é que muitas organizações ainda não sabem usar a ferramenta de forma dialógica, sendo cativas do modelo de comunicação unidirecional, buscando aplicar o mesmo modelo analógico à realidade digital. Observase muita propaganda invasiva e nesse ambiente as pessoas se incomodam em receber conteúdos persuasivos ou impositivos. Nesse espaço, o consumidor é quem escolhe o que quer ver e a hora em que deseja apreciar informações de seu interesse.

O consumidor atual não está mais na internet apenas para participar de uma comunidade. Ele interage, publica, cria vídeos, compartilha, influencia e é influenciado. "Quando compradores e vendedores trocam mais informações, o preço se torna fluido" (Tapscott, 2010, p. 257), o preço perde o status de inalterável e passa a ser negociável. A marca também assume uma nova posição no mercado, passando a ser mais que palavra ou imagem, e se converte em uma arquitetura baseada em integridade, honestidade, confiabilidade, consideração e transparência. A comunicação sai do modelo de promoção, mídia unidirecional e padronizada, para um modelo multidirecional e dialogal.

\section{A COPARTICIPAÇÃO NA PRÁTICA}

Algumas marcas já demonstram estar inseridas nesse conceito de coparticipação, como é o caso da Fiat que, no ano 2010 , lançou o Novo Uno como fruto de um intenso diálogo entre os designers do Centro Estilo Fiat para América Latina e do Centro Estilo Fiat da Itália e os consumidores. Seguindo essa mesma linha de participação, a marca lançou um vídeo em 2014, centrado na cantora de músicas pop Anitta e em seus dançarinos. Foi criado um primeiro vídeo', em que a cantora convidava os internautas a participarem da gravação da propaganda da marca, e divulgou-se o mesmo nas redes sociais. No vídeo, a cantora ensinava os passos da dança e, ao final, um link remetia o interessado em participar do concurso para um blog da marca, com toda a estrutura virtual para a gravação do filme. Alguns vídeos foram selecionados e utilizados na gravação da propaganda. Ou seja, o consumidor participava da produção publicitária da marca. A filosofia que embasa tal atitude é a de que, quando o indivíduo é inserido na produção de algo, ele sente satisfação em divulgar para seus amigos; trata-se da interação de fato. 0 poder de influência de compra de uma pessoa comum sobre a outra é tão grande que, segundo Ben McConnel e Jackie Huba (2006), há poucas chances de não obter êxito.

As pessoas costumam, inconscientemente, influenciar as outras a comprar algum produto ou serviço que a fez sentir-se bem, assistir a um filme de que gostou, frequentar determinado local que the proporcionou prazer, e até mesmo experiências indesejáveis são compartilhadas. No caso da propaganda da Fiat, o primeiro vídeo com o apelo da cantora para a participação, ocorreu em outubro de 2014 e obteve 115 mil visualizações. A propaganda oficial ${ }^{2}$ foi lançada no Youtube em novembro e um mês após a divulgação, as estatísticas apresentavam 3,5 milhões de visualizações. A iniciativa criou um clima envolvente com os consumidores, que, além de enviarem suas participações para a Fiat, também publicaram diversos vídeos no Youtube com a dança intitulada Happy de Série gravada por eles mesmos. A cantora Anitta também não foi escolhida por acaso; seu 


\section{ANO $12 \cdot$ NÚMERO $22 \cdot 1^{10}$ sem. $2015 \cdot$ ORGANICOM \\ DISCURSOS ORGANIZACIONAIS: AS RELAÇÕES DE CONSUMO NO AMBIENTE DAS REDES SOCIAIS DIGITAIS}

perfil tem muita similaridade com a imagem pretendida para o carro, que, de acordo com os designers da marca, segue uma tendência pop. A cantora também tem uma grande popularidade entre seus públicos, o que ajudou no sucesso da propaganda.

Essa interação com o usuário é sem dúvida uma forma criativa de atrair a atenção do consumidor para a marca, levando-0 ao engajamento e ao compartilhamento pelas redes sociais. 0 consumidor se torna um evangelista da marca, ele se percebe nela, pois fez parte da construção. McConnel e Huba (2006, p. 15), apontam que a popularização dessa espécie de evangelismo mercadológico surgiu nos anos 1980 por meio de Guy Kawasaki e da Apple Computadores:

Kawasaki foi nomeado um "evangelista do software" em 1983, e seu trabalho era vender o sonho do Macintosh para programadores que criariam software para os computadores da Apple. 0 sonho era aumentar a produtividade e a criatividade das pessoas que usavam computadores pessoais. O Macintosh era um produto revolucionário por sua facilidade de uso e desenho singular, atraindo críticas favoráveis de seus primeiros clientes. 0 fervor e o zelo dos evangelistas de software, como Kawasaki, promoveram uma imagem de uma empresa que queria mudar o mundo.

Com a chegada da Web 2.0, a Apple permaneceu utilizando os consumidores como evangelistas. No Youtube é possível encontrar diversos vídeos de garotos da Geração Internet, trazendo as novidades da marca em forma de depoimentos e notícias. 0 curioso da estratégia da marca é que os consumidores são tão apaixonados pelos produtos que não se importam em madrugar nas filas das lojas para adquirir o mais novo item de série. No lançamento do Iphone 6 na Austrália, um garoto virou notícia ao ser o primeiro a comprar o produto da marca: ainda emocionado pela aquisição, derrubou o aparelho no chão no momento da entrevista em rede de televisão. Após o ocorrido, o fato percorreu o mundo da internet por meio de compartilhamentos e comentários de outros usuários.

O sonho de toda empresa é atrair multidões de clientes para comprarem seus produtos. Com isso, focam os esforços na multidão e deixam muitas vezes de fidelizar aqueles que acreditam ter conquistado. Os evangelistas nos ensinam que as organizações precisam fortalecer em primeiro lugar o vínculo com os que já são consumidores de seus produtos e voluntariamente eles se tornarão verdadeiros seguidores e propagandistas dos conceitos e valores daquela que acreditam ser "a boa nova" do mercado, a novidade que o seu amigo precisa conhecer.

0 evangelista de marketing é alguém apaixonado, entusiasmado; quando fala sobre o produto em que acredita, "os olhos dele se iluminam e sua voz tem um toque de emoção. A outra pessoa por sua vez decide experimentar o produto porque confia nele, suas histórias se conectam" (McConnel; Huba, 2006, p. 3). 0 amor à marca é a principal causa de o consumidor evangelista difundi-la entre seus companheiros.

Os usuários de produtos da Apple são considerados pela marca como applemaníacos, pessoas que amam e fazem qualquer coisa para se manterem atualizadas sobre os lançamentos da marca. A marca é tão querida pelos seus consumidores que voluntariamente são criados posts nas redes sociais e compartilhamento de conteúdos, além de vídeos explicativos de como explorar todos os recursos que os aparelhos oferecem. Nesse ambiente colaborativo, a característica relacional do ser humano é manifestada constantemente em cada postagem, comentário ou compartilhamento de conteúdos. 0 indivíduo é compelido a manter-se ativo, influente e participativo na sua rede de relacionamentos para sentir-se vivo e parte da sociedade. Assim, a ideia de colaboração é consumida pelos participantes dessa sociedade em rede como requisito fundamental de sobrevivência e reconhecimento. As organizações também são inflamadas a entrar nessa cultura participativa, visto que essa é uma estratégia infalível, pois coloca o indivíduo como um ator social importante para a criação de seus produtos 


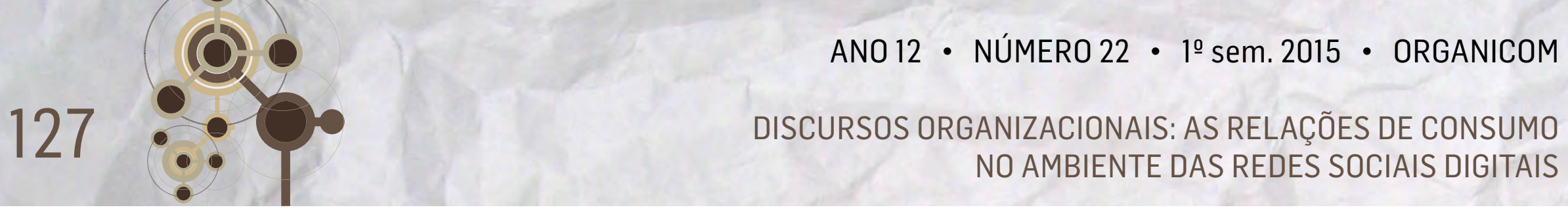

e serviços. Nessa cultura, o consumidor é cortejado a opinar e participar ativamente da construção de novos produtos e propagandas e também no compartilhamento voluntário de conteúdos pelas redes sociais, tornando essa modalidade parte de um processo relacional da nova era da comunicação digital.

\section{CONSIDERAÇÕES FINAIS}

0 processo que insere o indivíduo na criação de produtos e serviços e até mesmo da publicidade é um fator que está obrigando as organizações a se remodelarem no que elas já conheciam como comunicação, pois todo o conhecimento e toda a prática se pautavam numa linguagem unidirecional e controlada pela mídia de massa, que manipulava os consumidores a agirem conforme seus padrões e valores. Na sociedade da informação em que estamos imersos, em que a tecnologia proporcionou 0 poder interacional ao indivíduo, a comunicação foi desmassificada e agora cada pessoa que possua as condições necessárias de acessibilidade às tecnologias e às diferentes plataformas pode produzir seus próprios conteúdos e divulgar para quem quiser. Há uma plateia cada vez maior e ávida por interação e compartilhamento de conhecimentos. Assim, a mídia de massa vai convergindo para as mídias individuais e transformando a maneira como as empresas e sociedades utilizam as informações para inovação e criação de valores.

A atração voluntária do indivíduo por participar dos processos relacionais recebeu visibilidade após o advento das redes sociais, mas a verdade é que o diálogo sempre fez parte da vida do ser humano. Os sujeitos que participam do jogo da linguagem, interlocutores do processo comunicacional, se relacionam a partir de determinadas condições estabelecidas e papéis a serem desempenhados, construindo um fenômeno particularmente dialógico. Mesmo tratando-se de um ambiente virtual, as relações são formadas com base nos valores da sociedade em que vivem. Esses valores escoam pelas redes sociais digitais em que o indivíduo tem o poder de mostrar ser aquilo que não é, mas sempre sonhou ser. Por isso, muitas vezes, compartilhar uma determinada marca pode lhe conferir prestígio entre os amigos, levá-lo a almoçar num belo restaurante ou mesmo fazêlo publicar fotos de viagens incríveis, colocando-o numa posição socialmente favorável em sua rede de relacionamentos.

Essa é a cultura colaborativa que permeia a sociedade pós-moderna. 0 consumidor participa da produção enviando ideias para as organizações, sugerindo sabores, formatos, novos produtos e até mesmo participando de suas propagandas.

As organizações inteligentes precisam entender que os clientes de agora não são apenas consumidores, mas são peça fundamental para o seu negócio. Adaptar-se a essa nova configuração da comunicação digital não é uma questão de modismo. É preciso elaborar planejamento estratégico de como falar com essa Geração Internet, como trazê-la para junto de si e encorajá-la ao engajamento e à propagação de conteúdos favoráveis à marca pelas redes sociais on-line.

\section{REFERÊNCIAS}

BAKHTIN, Mikhail Estética da criação verbal. 2. ed. São Paulo: Martins Fontes, 1997.

BUENO, Wilson da Costa (Org.). Comunicação empresarial: planejamento e gestão. São Paulo: All Print editora, 2011.

CASTELLS, Manuel. A sociedade em rede: do conhecimento à acção política. Lisboa: Imprensa Nacional-Casa da Moeda, 2006. 
COMPRADOR do primeiro iPhone 6 derruba aparelho no chão. Disponível em: <https://www.youtube.com/ watch?v=UrOfDTEjvRQ >. Acesso em: 25 fev. 2015.

DI FELICE, Massimo. Do público para as redes: a comunicação digital e as novas formas de participação social. São Caetano do Sul, SP: Difusão, 2008.

FIAT lança novo clipe para Novo Uno 2015 com Anitta. Disponível em: <http:// www.portaldapropaganda.com.br/portal/ component/content/article/16-capa/43988-fiat-lanca-novo-clipe-para-novo-uno-2015-com-anitta>. Acesso em: 25 fev. 2015.

INAUGURAÇÃO da Primeira AppleStore do Brasil! [HD]. Disponível em: <https://www.youtube.com/watch?v=ipuV7cEUdDA>. Acesso em: 25 fev. 2015.

JENKINS, Henry. Cultura da convergência. Trad. de Susana Alexandria. São Paulo: Aleph, 2008.

KERCKHOVE, Derrick de. A pele da cultura. São Paulo: Annablume, 2009.

LI, Charlene; BERNOFF, Josh. Fenômenos sociais nos negócios, groundswell: vença em um mundo transformado pelas redes sociais. Trad. de Sabine Alexandra Holler. Rio de Janeiro: Campus, 2012.

McCONNELL, Ben; HUBA, Jackie. Buzzmarketing: criando clientes evangelistas. São Paulo: MBooks, 2006.

McLUHAN, Marshall. Os meios de comunicação como extensões do homem. Trad. de Décio Pignatari. 8. ed. São Paulo: Cultrix, 1996.

NOVIDADES: iPhones Maiores, AppleWatch, NFCe mais!!Disponível em: <https://www.youtube.com/watch?v=SVnYiDt3Bto>. Acesso em: 25 fev.2015.

NOVO Uno 2015 | Clipe \#HappyDeSérie com Anitta. Disponível em:<https:// www.youtube.com/watch?v=20Ap5CHx-V0>. Acesso em: 25 fev. 2015.

NOVO Uno 2015 | Happy de Série com Anitta. Disponível em: <https://www.youtube.com /watch?v=uAZaY_SLal4>. Acesso em: 25 fev. 2015.

O QUE SE ESPERA do evento da Apple dia 09/09??? Disponível em: <https://www.youtube.com/watch?v=wg6KQXx1758>. Acesso em: 25 fev. 2015.

PÊCHEUX, Mochel. Análise automática do discurso (AAD-69). Trad. de Eni Orlandi. In: GADET, Françoise; HAK, Tony (Org.). Por uma análise automática do discurso: uma introdução à obra de Michel Pêcheux. Campinas: Editora da Unicamp, 1990.

PESQUISA brasileira de mídia 2014. Disponível em: <http://observatoriodaimprensa. com.br/download/ PesquisaBrasileiradeMidia2014.pdf>. Acesso em: 25 fev. 2015.

SANTAELLA, Lucia. Navegar no ciberespaço: o perfil cognitivo do leitor imersivo. São Paulo: Paulus, 2004.

SCOTT, David M. As novas regras do marketing e de relações públicas. Trad. de Ricardo Bastos Vieira e Ana Maria Badaró. Rio de Janeiro: Campos, 2008. 


\section{ANO $12 \cdot$ NÚMERO $22 \cdot 1^{\text {os }}$ sem. $2015 \cdot$ ORGANICOM \\ DISCURSOS ORGANIZACIONAIS: AS RELAÇÕES DE CONSUMO NO AMBIENTE DAS REDES SOCIAIS DIGITAIS}

TAPSCOTT, Don. A hora da geração digital: como os jovens que cresceram usando a internet estão mudando tudo, das empresas aos governos. Trad. de Marcelo Lino. Rio de Janeiro: Agir Negócios, 2010.

TOFFLER, Alvin. A terceira onda. Trad. de João Távora. 32a .ed. Rio de Janeiro: Record, 2014.

VILCHES, Lorenzo. A migração digital. São Paulo: Loyola, 2003.

Artigo recebido em 03.03.2015 e aprovado em 14.05.2015. 